\title{
The Role of Village Surveillance Officer to Prevent Dengue Hemorrhagic Fever
}

\author{
Sunarsih $^{1}$, Kuntoro ${ }^{2}$, Chatrin U.W ${ }^{3}$, Nugroho Susanto ${ }^{4}$ \\ ${ }^{1}$ Public Health Office of Kendari, Kendari, Indonesia \\ ${ }^{2,3}$ Public Health Faculty, Airlangga University, Surabaya, Indonesia \\ ${ }^{4}$ Public Health Faculty, Universitas Respati Yogyakarta, Yogyakarta, Indonesia
}

\begin{tabular}{l} 
Article Info \\
\hline Article history: \\
Received May 31, 2016 \\
Revised Aug 20, 2016 \\
Accepted Aug 26, 2016 \\
\hline
\end{tabular}

\section{Keyword:}

Container index

Dengue control

Village surveillance officer

\begin{abstract}
Dengue is a major public health problem in Indonesia. The program of elimination of mosquito breeding places is still low. This study was aimed to analyze the effectiveness of village surveillance officer for decrease container index. Study design was quasi experiment. The intervention included: community workshops; community involvement in clean-up campaigns; and distribution of information, education and communication materials in the village surveillance officer. Data were analyzed with $t$ test, and path way analyzed. There is significantly differences knowledge, attitude, behavior, sanitation, and container index $\mathrm{p}<0.05$. Based on the path analysis was concluded that village surveillance officer increased knowledge, attitude, behavior, sanitation and container index. Surveillance village officer is concluded to be more effectively decreased of larva index through community behavior. Surveillance village officer is important because it effectively the coverage of larva index through community behavior participation.
\end{abstract}

Copyright $\left({ }_{0} 2016\right.$ Institute of Advanced Engineering and Science. All rights reserved.

\section{Corresponding Author:}

Sunarsih,

Public Health Office of Kendari Province,

Kendari, Indonesia.

Email:narsihunair@gmail.com

\section{INTRODUCTION}

Dengue haemorrhagic fever (DHF) is still a problem in many parts of the world. DHF is a disease that has serious clinical manifestations. It is estimated that dengue disease affects about 70.3 to 130 per 100000 people. DHF is a disease with a relatively high mortality rate. Case fatality rate (CFR) dengue in Indonesia reached $0.98 \%$ [1]. It is reported that CFR of dengue reached $1.94 \%$. Indonesian government had made efforts to control dengue, such as spraying, eradicating dengue vector breeding place; however the results are still not as expected [2]. The ssuccess of the program of elimination of mosquito breeding places is still low since there is no public participation effort in vector control. The participation of community is way to reduced larva index [3]. The government of Indonesia had made dengue control programs which are related with community such as vector control with promotion aspects. But, none of the promotion programs involving community participation.

The ecosystems approach to human health (Eco-health) has been a successful eco-bio-social model used in vector control programs at a local level. Communities have been vocal about the need for alternative vector control and dengue prevention strategies. Common challenges remain in ensuring sustainability of social mobilization and social communication elements, as well as operational challenges in assuring adequate coverage of vector source reduction campaigns and reducing dependence on insecticides. Public participation is a key factor for the programs to be success and sustainable among community process in order activities [4]. 
Previous study was concluded that low public participation makes one particular program is not sustainable. This special issue reports findings of a research and capacity building program on innovative community-based vector control interventions for improved dengue and Chagas disease prevention. This will play a crucial function in defining locally relevant and appropriate interventions with the prospects for sustainable control of vector populations. Participation of public is the main key in community mobilization for dengue control program [5]. Role community participation is very important, such as officer surveillance village.

Various efforts to increase community participation through increased surveillance strategy for community role activities. Be interested inapplication of community participation are more effective in solving various problems in society, especially in the prevention of dengue fever [6]. Village surveillance officer is a key factor for sustaining any health programs implemented into the community. This study was aimed to analyze the effectiveness of village surveillance officer impact on behavior change in community based dengue prevention programs.

\section{RESEARCH METHOD}

Research was used quasi experiment with pre test-post test control group design. Surveillance officer was required of community as 18 surveillance officer in local areas study. The intervention included: dengue haemorrhagic fever: signs or symptoms, mode of transmission, and survey larvae. Three days intervention was conducted to 18 participation (surveillance officers). Component of intervention included dengue disease natural history of disease, prevention of dengue, risk factor of dengue infection, training of trainer for dengue to community, larva survey, and surveillance system reported.

Sample was collected from 6 villages; sample village was collected with cluster random sampling. Such as village were collected 3 surveillance officer. Role of surveillance for coordinating for around areas of village. Data was collected with interviews to house hold and observation. Instrument divide knowledge, attitude, behavior, sanitation and larva index. Data shown with table, figure and narration. Data were analyzed with paired $t$ test, independent $t$ test and path way analyzed with significant level $95 \%$ confidence interval.

\section{RESULTS}

Based on the analysis of village surveillance officer for knowledge, attitude, behaviour, sanitation and larva index, the results are as shown below. Based on Table 1 was concluded that in the control group there was no significant difference between pre and post intervention in the variable knowledge, attitudes, behavior, sanitary and larva index can be judged from the $\mathrm{p}>0.05$.

Table 1. Differences Knowledge, Attitude, Behavior, Sanitation and Larva Index between Pre and Post Test for Control Group

\begin{tabular}{|c|c|c|c|c|}
\hline \multirow{2}{*}{ No } & \multirow{2}{*}{ Variable } & \multicolumn{2}{|c|}{ Control Group } & \multirow{2}{*}{$P$} \\
\hline & & Pre & Post & \\
\hline 1 & Knowledge & $58.29 \pm 12.0$ & $57.22 \pm 11.7$ & 0.07 \\
\hline 2 & Attitude & $53.94 \pm 14.74$ & $53.22 \pm 14.39$ & 0.253 \\
\hline 3 & Action & $23.84 \pm 27.11$ & $24.61 \pm 27.13$ & 0.529 \\
\hline 4 & Sanitary & $52.63 \pm 14.23$ & $52.52 \pm 13.21$ & 0.910 \\
\hline 5 & Container Index & $45.82 \pm 26.01$ & $46.47 \pm 23.77$ & 0.696 \\
\hline
\end{tabular}

Based on Table 2 was concluded that In the intervention group, there are significant differences between pre and post intervention in the variable knowledge, attitudes, actions, sanitary and CI can be seen from the value of $\mathrm{p}<0.001$.

Table 2. Differences Knowledge, Attitude, Behavior, Sanitation and Larva Index between pre and post test for Intervention Group

\begin{tabular}{|c|c|c|c|c|}
\hline \multirow[b]{2}{*}{ No } & \multirow{2}{*}{ Variable } & \multicolumn{2}{|c|}{ Intervention Group } & \multirow{2}{*}{$\mathrm{P}$} \\
\hline & & Before & After & \\
\hline 1 & Knowledge & $57.47 \pm 11.66$ & $67.80 \pm 11.3$ & 0.000 \\
\hline 2 & Attitude & $53.55 \pm 14.09$ & $71.18 \pm 12.13$ & 0.000 \\
\hline 3 & Action & $30.00 \pm 25.23$ & $55.70 \pm 21.31$ & 0.000 \\
\hline 4 & Sanitary & $51.09 \pm 14.75$ & $58.97 \pm 13.22$ & 0.000 \\
\hline 5 & Container Index & $44.77 \pm 26.57$ & $39.05 \pm 22.42$ & 0.000 \\
\hline
\end{tabular}


Table 3 was concludes that there is a difference between the treatment group and the control group in the variable knowledge, attitudes, actions, sanitary and container index $\mathrm{p}<0.0001$.

Table 3. Differences Average Knowledge, Attitude, Action, Sanitary and Container Index between Intervention Group and Control Group

\begin{tabular}{llccccc}
\hline No & \multicolumn{1}{c}{ Variable } & $\mathrm{N}$ & $\begin{array}{c}\text { Experiment } \\
\mathrm{N}=780 \\
\text { Mean } \pm \text { SD }\end{array}$ & $\begin{array}{c}\text { Control } \\
\text { N=260 } \\
\text { Mean } \pm \text { SD }\end{array}$ & T & P \\
\hline 1 & Knowledge & 780 & $62.64 \pm 12.62$ & $59.12 \pm 12.51$ & 3.900 & 0.000 \\
2 & Attitude & 780 & $62.37 \pm 15.82$ & $55.28 \pm 15.06$ & 6.32 & 0.000 \\
3 & Action & 780 & $42.85 \pm 26.65$ & $28.17 \pm 28.08$ & 7.588 & 0.000 \\
4 & Sanitary & 780 & $55.03 \pm 14.54$ & $44.20 \pm 20.68$ & 2.289 & 0.000 \\
5 & Container index & 780 & $41.91 \pm 24.74$ & $44.20 \pm 20.68$ & -1.345 & 0.000 \\
\hline
\end{tabular}

Path analysis was conducted for factors related with the coverage of container index, such as knowledge, attitude, action, sanitary, and container index. The analysis resulted that the village surveillance officer significantly affect knowledge $(\mathrm{t}=-5.47)$, attitudes $(-7.91)$, actions $(-9.72)$, sanitation $(-2.39)$ and container index (-1.98). Based on the results of the path can be concluded that the intervention is more effective decreased container index through action in the community.

\subsection{Discussion}

Based on analyzed was performance that differences for knowledge, attitudes and actions between pre and post intervention village surveillance officer. This situation can be caused by the presence of village surveillance officer affect the dissemination of information to other people in the community so that the knowledge society in the environment has increased. This is consistent with previous study that [7] found a mean to differences between the control group (8:01) and the treatment group (6.94). Previous studying Brazil showed that there are significant differences between container index for intervention and control group

$\mathrm{p}=0.020$. This condition can be caused by participation in vector control efforts affect the surrounding community to take action [8].

Previous study was reviewed journal of the impact of community participation in dengue virus decline concluded that the effectiveness of the prevention of dengue disease depends on an understanding of the many factors that affect prevention and environmental factors [9]. Previous study conducted the research community participation in prevention of dengue disease to 100 households in Machala Ecuador showed that there are significant differences between the central bank before the intervention and after the intervention $\mathrm{p}=>0.05[10]$.

Based on environmental sanitation was found that there are significant differences between pre and post intervention. This situation can be caused by the appointment of village surveillance officer may be a public figure in the attitude and actions of the community so that the activity of surveillance officer village is followed by other community members in the neighbourhood. This is consistent with previous study who did research on the impact of vector control community participation in the state of entomology in Brazil showed that there are significant differences between intervention and control $p=0.029$. There are significant differences between before and after intervention on indicators container index $p=0.02$. This condition can be caused by participation in vector control efforts affect the surrounding community to take action [8].

Previous study shown Opinion Caprara et al [8] Community participation in vector control efforts affect the surrounding community to take action to keep the fish, drain the tub, closing cans in their home environment. Community participation and management of vector density environments can decrease Ae. aegypti [8]. Approach to environmental participation on sale regularly in the vector control services and DHF. This situation gives the conclusion that the fight against larvae without the community's role can't succeed.

Community participation in the operational surveillance system can have a variety of functions, among others, as the executor of surveillance systems and as agents of behavioral change for society as a surveillance officer can as agents of behavioral change for the community. Surveillance officer chosen can affect a variety of things for the people around the residence officers with a variety of approaches.

Surveillance role of the community as the village office can perform various activities such as the monitoring of surveillance systems larvae, mosquito density monitoring, recording and reporting on the vector of vectors and dengue fever patients. Some activities that can be performed by a surveillance officer village office can assist operational implementation of the surveillance system. 
Previous study stated that surveillance is based on signs and symptoms can be expedited as soon as possible preventive measures, it is very meaningful in the detection of outbreaks, and timely prevention efforts [11]. Surveillance syndrome further improved early detection system for public health because of the signs and symptoms of the disease can be immediately reported by a surveillance officer [12].

\section{CONCLUSION}

Appropriate surveillance system for disease dengue vector mosquito transmission is more effective by involving the community. Village surveillance officer effectively for decreased container index through action preventive dengue control. Village surveillance officer potential for behaviour change agency for dengue disease.

\section{REFERENCES}

[1] WHO, "Situation of Dengue/Dengue Haemorrhagic Fever in the South-East Asia Region: Prevention and Control Status in SEA Countries," 2006.

[2] Indonesia Department, "Development and Future Challenges in health Promotion in Indonesia," Jakarta, Health Department of the Republic of Indonesia, 2009.

[3] A. Sumantri, "Environmental Based Prevention Model on The Dengue Hemorrhagic Fever Dissemination in The DKI Jakarta Province,"Journal of Natural Sciences Research, vol/issue: 2(3), 2012.

[4] H. Nadesul, "Easy Ways to Beat Dengue,"Jakarta, Compass Book Publishers, 2007.

[5] J. H. Dalton, et al., "Community Psychology: Linking Individuals and Communities," Australia, Wadsworth, 2001.

[6] M. Eriksson, "Social Capital, Health and Community Action - Implication for Health Promotion," Sweden, Umea University, 2010.

[7] C. Basso, et al., "Improved dengue fever prevention through innovative intervention methods in the city of Salto, Uruguay,"Trans R Soc Trop Med Hyg, vol. 109, pp. 134-142, 2015.

[8] A. Caprara, et al., "Entomological impact and social participation in dengue control: a cluster randomized trial in Fortaleza,"Brazil Trans R Soc Trop Med Hyg, vol. 109, pp. 99-105, 2015.

[9] L. R. Feldstein, et al., "Dengue on islands: a Bayesian approach to understanding the global ecology of dengue viruses,"Trans R Soc Trop Med Hyg, vol. 109, pp. 303-312, 2015.

[10] K. M. Foster, et al., "Integrating participatory community mobilization processes to improve dengue prevention: an eco-bio-social scaling up of local success in Machala, Ecuador,"Trans R Soc Trop Med Hyg, vol. 109, pp. 126-133, 2015.

[11] P. Yan, et al., "A Review of Public Health Syndromic Surveillance Systems,"Department of Management Information Systems, University of Arizona, Tucson, 2006.

[12] L. Josseran, et al., "Performances of a syndromic surveillance system during a heat wave,"Advances in Disease Surveillance, vol. 4, pp. 253, 2007. 